\title{
SÍNDROME DE ASPERGER: A SINGULARIDADE DA CRIANÇA E A IMPORTÂNCIA ATIVA DO PSICOPEDAGOGO NA EDUCAÇÃO INFANTIL
}

\author{
ASPERGER SYNDROME: THE CHILD'S SINGULARITY AND THE ACTIVE \\ IMPORTANCE OF PSYCHOPEDAGOGUE IN CHILDHOOD EDUCATION
}

\section{Helen Beatriz Marques Chrysostomo ${ }^{1}$}

RESUMO: As investigações e evidências científicas apontam para necessidade de expandir o conhecimento acerca da síndrome de Asperger. Esta pesquisa objetivou esclarecer como é a criança portadora da síndrome de Asperger bem como, quais são as suas necessidades e peculiaridades. A metodologia utilizada é bibliográfica, de autores que discutem e contribuem com seus resultados sobre o tema abordado que é de extrema relevância para os educadores, profissionais de saúde, familiares e para as próprias crianças que passam a ser compreendidas e respeitadas em sua singularidade. Por fim, e não menos importante, deve-se considerar a atuação do psicopedagogo na educação infantil, como um profissional que auxiliará nas intervenções precoces promovendo a interação social satisfatória, viabilizando o ensino aprendizagem e potencializando o bem-estar de todos envolvidos dentro contexto.

Palavras-Chave: Síndrome de Asperger. Psicopedagogia. Educação Infantil. Singularidade.

ABSTRACT: Investigations and scientific evidence point to the need to expand knowledge about Asperger syndrome. This research aimed to clarify what the children with Asperger syndrome looks like, as well as what are their needs and peculiarities. The methodology used is bibliographic, by authors who discuss and contribute their results on the topic addressed, which is extremely relevant for educators, health professionals, family members and for the children themselves, who come to be understood and respected in their uniqueness. Finally, and not least, one should consider the role of the psycho pedagogue in early childhood education, as a professional who will assist in early interventions by promoting satisfactory social interaction, enabling teaching and learning and enhancing the well-being of all involved within context.

Keywords: Asperger syndrome. Psycho pedagogy. Child education. Singularity.

1 Psicóloga. Especialista em Gestão de Saúde Mental. Pós-Graduando em Psicopedagogia e Ludopedagogia.E-mail: hb.chrys@hotmail.com. 


\section{INTRODUÇÃO}

Qual profissional não gostaria de obter mais informações acerca de comportamentos atípicos colaborando com diagnósticos e intervenção precoce? E se a informação do que é esses comportamentos menos adaptáveis e de quais profissionais tem a competência de auxiliar e desenvolver as crianças atípicas estivesse acessível também ao conhecimento das famílias?

Este estudo visa compreender e acolher as crianças em sua singularidade, viabilizar aos pais e profissionais da saúde e educadores maior esclarecimento acerca da Síndrome de Asperger, ou Autismo Leve, e a importância do Psicopedagogo como profissional capaz de identificar quais são os problemas no processo de aprendizagem ou de interação social e desenvolver ações de prevenção ou de correção dos problemas encontrados, oferecendo diagnósticos e o melhor tratamento.

Entender a Síndrome de Asperger (AS) e o papel do Psicopedagogo na educação infantil é o tema deste estudo, e escorreremos pelo assunto de forma que você leitor, seja profissional da saúde, educador ou pais de crianças que apresentam comportamentos atípicos, tenha condições de discernir. Cabe ressaltar, porém, que em caso de identificação você procure uma equipe multidisciplinar de profissionais especializados para que seja feito o diagnóstico e receber as orientações pertinentes, pois cada criança é única.

A metodologia utilizada é bibliográfica, de autores que discutem sobre o tema abordado, cuja temática é de extrema relevância para o contexto atual e cada vez mais deve ser observada e discutida entre pais, educadores, pesquisadores e profissionais da área da saúde. Para o levantamento e seleção de dados recorremos às bibliotecas acadêmicas online e o critério de inclusão dos documentos se deu por idioma em português, e aqueles que contemplavam a ideia principal que é de descrever o que é a Síndrome de Asperger e a atuação do Psicopedagogo neste contexto. Foram excluídos estudos realizados anterior ao ano de 2006. E incluído a quinta edição, em português, do principal apoio referencial às patologias da mente e porque não dizer da alma, o Manual Diagnóstico e Estatístico de Transtornos Mentais.

Começamos, portanto, por apresentar o Manual Diagnóstico e Estatístico de Transtornos Mentais, o DSM, em sua quinta edição, publicado em maio de 2013 (versão em português - 2014). Este é um guia de apoio para demarcação de doenças psíquicas. É a atual referência para a prática clínica, contém elementos úteis para todos os profissionais ligados a saúde mental, como psiquiatras, médicos, psicólogos, assistentes sociais, enfermeiros, consultores, especialistas da área forense e legal, terapeutas ocupacionais e de reabilitação, educadores e, outros profissionais. Veja o que diz o referido manual acerca dos transtornos mentais, DSM-5 (2014; p.20) 
Um transtorno mental é uma síndrome caracterizada por perturbação clinicamente significativa na cognição, na regulação emocional ou no comportamento de um indivíduo que reflete uma disfunção nos processos psicológicos, biológicos ou de desenvolvimento subjacentes ao funcionamento mental.

De posse da definição acima do que caracteriza um transtorno mental, nos cabe compreender o que é o normal ou saudável, sendo assim, sugerimos que acolha as definições de Durkheim (1985) citado em Sena (2014), um determinista social, influenciado pelo evolucionismo. $\mathrm{O}$ autor refere que a sociedade molda as ações das pessoas e a recompensa à medida que desempenham seus papéis sociais. Em seu livro de I895, As Regras do Método Sociológico, Durkheim reserva o capítulo terceiro à distinção entre o normal e o patológico, aponta que se as pessoas que tentam contrariar a sociedade, esta aciona controles e repressão. Entendemos por esse princípio como normais ou saudáveis os comportamentos que apresentam as respostas mais gerais e daremos aos outros modelos de interação o nome de atípicos ou de patológicos.

Poderíamos nos debruçar sobre diversos autores para tentar exemplificar o saudável do patológico, mas essa é uma discussão muito antiga e que ainda não tem uma exata definição. Importante aqui é ajuizar que todo indivíduo que possui dificuldade ou restrição de corresponder à sociedade poderá sofrer sérios prejuízos em diferentes áreas de sua vida, vez que somos também seres sociáveis.

Corrobora a Constituição da Organização Mundial da Saúde (OMS), em sua introdução, de saúde definiu como: "estado de completo bem-estar físico, mental e social e não consistindo somente da ausência de uma doença ou enfermidade". Ao nos encontrarmos com tal declaração temos a surpreendente e complexa conceituação. Essa é mais do que uma definição, é um verdadeiro desafio a se alcançar!

O Sentimento gerado pelos estudos encontrados acerca dos temas aqui abarcados é de que estamos sendo instigados ao desapego de velhos preconceitos e a demissão do pensamento de que somente a criança saudável goza de bem-estar físico, mental e social. Felizmente, estamos permitindo a entrada em nossas vidas, em nossas práticas, de novos paradigmas para ampliarmos nossa consciência e verificarmos que todos nós, de todas as áreas do conhecimento, estamos implicados na promoção da saúde. Além disso, assumir a responsabilidade de que a criança que apresenta comportamento atípico só não será saudável se a sociedade não buscar compreendê-la, respeitá-la e se formos omissos de não trabalharmos para fornecer maneiras de que estes infantes diferenciados possam interagir com o meio ambiente nos quais estão inseridos. Faz-se relevante também darmos a oportunidade às crianças ditas atípicas o direito de nos ensinar a ter um olhar sobe novo prisma. 
Ao exercitar o pensamento a despeito das questões até aqui mencionadas poderíamos falar de vários transtornos e síndromes que requerem acompanhamento dentro da inclusão e das carências das famílias e instituições, principalmente as redes de educação infantil no Brasil. Porém não caberia aqui, logo, nosso viés como está direcionado; será de identificação da criança com Síndrome de Asperger e o papel do Psicopedagogo na educação infantil.

\section{DESENVOLVIMENTO}

Ao admitir que o desafio de atuar com a deficiência é social e culturalmente aprendido não há razão para ignorar o fato de que somos atuantes e de que influenciamos as crianças ditas normais. Sendo assim, nosso dever é auxiliar a formar valores sob novo prisma. Daqui surge a motivação para conhecer e divulgar as singularidades dos infantis com Asperger e para elas subsidiar práticas educativas eficazes. Propomos que o caminho para e educação infantil seja abarcada pela cultura da alteridade, da validação do diferente, da estima de conhecer e acolher a beleza que existe em cada criança.

Para compreender qual a importância ativa do Psicopedagogo na educação infantil frente à criança com Síndrome de Asperger faz-se urgente identificar as características dessas crianças. Com esse intuito abordamos a seguinte dúvida: qual a diferença do Transtorno do Espectro Autista (TEA) e a Síndrome de Asperger (SA)?

Buscando a compreensão, analisou-se diversos estudos que se complementaram entre si a respeito da questão norteadora quanto às características e diferencial diagnóstico entre TEA e SA., e também coube aqui, acrescentar as habilidades e desafios de aprendizagem das crianças com esses transtornos.

Santos e Melo (2019), descreveram as crianças Autistas como aquelas cujos comportamentos são característicos e é comum que elas não olham nos olhos de outras pessoas, demonstram dificuldades na interação com outras crianças, movimentos estereotipados e prezam por rotinas, etc. Esse mesmo estudo mencionou Klin (2006) definindo Autismo como:

O autismo, também conhecido como transtorno autistico, autismo da infância, autismo infantil e autismo infantil precoce, é o TID mais conhecido. Nessa condição, existe um marcado e permanente prejuízo na interação social, alterações da comunicação e padrões limitados ou estereotipados de comportamentos e interesses. As anormalidades no funcionamento em cada uma dessas áreas devem estar presentes em torno dos três anos de idade. Aproximadamente 6o a 70\% dos indivíduos com autismo funcionam na faixa do retardo mental, ainda que esse percentual esteja encolhendo em estudos mais recentes. Essa mudança provavelmente reflete uma maior percepção sobre as manifestações do autismo com alto grau de funcionamento, o que, por sua vez, parece conduzir a que um maior número de indivíduos seja diagnosticado com essa condição (KLIN, 2006, p. 4). 
Historicamente, o transtorno desintegrativo da infância foi apresentado por Heller, em 1908, que descreveu seis casos de crianças jovens que, posteriormente a um desenvolvimento supostamente normal nos primeiros três a quatro anos de vida, exibiram um severo prejuízo nas habilidades sociais e comunicativas, Heller indicou a condição como "dementia infantilis" (MERCADANTE, 2006) citado em (AMARAL, LYRIO, 2019).

O conceito do Autismo que conhecemos, ocorreu no ano de 1943, quando o médico psiquiatra Leo Kranner observou onze casos do que ele chamou de distúrbios autísticos do contato afetivo, analisandou que as crianças observadas apresentaram comprometimento de falar, se relacionar e interagir com o meio. Nas décadas de 1950 e I960 não havia concordância quanto à causa, muitas vezes os pais eram tachados de despreparados para criar filhos. Klin (2006) fez alusão a Michael Rutter (1978), contribuiu com uma definição cuja base foi em quatro critérios que ajudou o embasamento do diagnóstico do Autismo, sendo esta classificação um crédito para o conceito do Manual Diagnóstico e Estatístico de Transtornos Mentais (DSM- III), descritos, (KLIN, 2006, p. 4):

Atraso e desvio sociais não só como função de retardo mental; 2) problemas de comunicação, novamente, não só em função de retardo mental associado; 3) comportamentos incomuns, tais como movimentos estereotipados e maneirismos; e 4) início antes dos 30 meses de idade.

Santos e Melo (2019) mencionam a Sindrome de Asperger com base em Klin (2006) que definiu como:

\begin{abstract}
A Síndrome de Asperger (SA) caracteriza-se por prejuízos na interação social, bem como interesses e comportamentos limitados, como foi visto no autismo, mas seu curso de desenvolvimento precoce está marcado por uma falta de qualquer retardo clinicamente significativo na linguagem falada ou na percepção da linguagem, no desenvolvimento cognitivo, nas habilidades de autocuidado e na curiosidade sobre o ambiente. Interesses circunscritos intensos que ocupam totalmente o foco da atenção e tendência a falar em monólogo, assim como incoordenação motora, são típicos da condição, mas não são necessários para o diagnóstico (KLIN, 2006, p.8).
\end{abstract}

A síndrome de Asperger foi revelada pelo médico pediatra Hans Asperger, em 1943. Primeiramente, Asperger descreveu uma condição que chamou de Psicopatia Autística que é caracterizada pelas dificuldades relacionais, isolamento, mas linguagem prolixa e fala gramaticalmente correta, o que dificultava a percepção dos 
desvios comportamentais como indícios de um transtorno global. (SANTOS e MELO, 2019).

Os sintomas observados nas crianças com Síndrome de Asperger não são suficientes para preencher o prognóstico exigido para a constatação do Espectro Autista (KLIN, 2006). Os estudos relacionados a Síndrome de Asperger ainda são recentes, o que vale ressaltar é que a principal distinção possível de ser feita entre as duas síndromes é que infantos com Autismo, principalmente nos casos agudos, possuem obstáculos maiores que comprometem a possibilidade de uma vida independente (SANTOS e MELO 2019).

Para levantamento de Autismo cabe mencionar que é necessário considerar a singularidade de cada criança desta síndrome, pois além da variação dos níveis de intensidade, há expressão biológica e comportamental que mudam de um infanto para outro. Resumidamente, o Autismo é um transtorno neurocognitivo que compromete o desenvolvimento global da criança, geralmente, mas, nem sempre manifesto antes dos três anos de idade. O TEA controla e aviva a percepção aos detalhes. Esta peculiaridade pode ser fomentada, através de estímulos, em habilidades excepiconais, nas diversas áreas, como por exemplo, nas Artes, na Matemática, ou outras Ciências. (SANTOS e MELO, 2019).

Entretanto, o DSM-V propõe que a Síndrome de Asperger seja diagnosticada como Espectro Autista: "Indivíduos com um diagnóstico do DSM-IV bem estabelecido de transtorno autista, transtorno de Asperger ou transtorno global do desenvolvimento sem outra especificação devem receber o diagnóstico de transtorno do espectro autista" (DSM-V, 2014, p.5r).

Atualmente o Manual Diagnóstico e Estatístico de Transtornos Mentais (DSMV), desde 2014, define o Autismo do seguinte modo:

O transtorno do espectro autista caracteriza-se por déficits persistentes na comunicação social e na interação social em múltiplos contextos, incluindo déficits na reciprocidade social, em comportamentos não verbais de comunicação usados para interação social e em habilidades para desenvolver, manter e compreender relacionamentos. Além dos déficits na comunicação social, o diagnóstico do transtorno do espectro autista requer a presença de padrões restritos e repetitivos de comportamento, interesses ou atividades. Considerando que os sintomas mudam com o desenvolvimento, podendo ser mascarados por mecanismos compensatórios, os critérios diagnósticos podem ser preenchidos com base em informações retrospectivas, embora a apresentação atual deva causar prejuízo significativo (DSM-V, 2014, p. 32). 


\section{Para investigação e comprovação do Autismo o DSM-V salienta que:}

No diagnóstico do transtorno do espectro autista, as características clínicas individuais são registradas por meio do uso de especificadores (com ou sem comprometimento intelectual concomitante; com ou sem comprometimento da linguagem concomitante; associado a alguma condição médica ou genética conhecida ou a fator ambiental), bem como especificadores que descrevem os sintomas autistas (idade da primeira preocupação; com ou sem perda de habilidades estabelecidas; gravidade). Tais especificadores oportunizam aos clínicos a individualização do diagnóstico e a comunicação de uma descrição clínica mais rica dos indivíduos afetados. Por exemplo, muitos indivíduos anteriormente diagnosticados com transtorno de Asperger atualmente receberiam um diagnóstico de transtorno do espectro autista sem comprometimento linguístico ou intelectual (DSM-V, 2014, p. 32).

Cabe salientar que o diagnóstico da Criança Autista, assim como da Criança com Síndrome de Asperger ou transtorno global do desenvolvimento sem outra especificação, hoje TEA, deve ser realizado com base na subjetividade de cada criança e por profissionais especializados e habilitados. Não existem peculiaridades absolutamente distintas entre os autistas, as características variam de acordo com a individualidade. Quanto às semelhanças, as áreas afetadas pelo transtorno são: o ajustamento comportamental, aptidão social e os desafios da comunicação.

A dificuldade ou inabilidade social é base do comportamento de um Autista, sendo mais aparente que as demais. Os obstáculos na socialização são diversos, dos mais extremados, como o isolamento total, podendo ser um distanciamento intermediário, como as dificuldades sociais, ou podem ser ainda de características leves, quase imperceptíveis, difundindo-se com traços de personalidade. Esse último, mas não menos importante, exige alta competencia do profissional avaliador para aferir o diagnóstico de TEA leve e orientar o tratamento. (SILVA, GAIATO, REVELES, 2012, p.II).

Percebe-se que os maior desafio da criança portadora da Síndrome de Asperger é o fato da interação social, a maneira de interagir se relacionar e demonstrar sentimentos. Os infantos com SA são extremamente sinceros e a interpretação das palavras é no sentido denotativo, isto é, possuiem dificuldade em compreender as mensagens irradiadas por meio da linguagem corporal, já que habitualmente não olham nos olhos e, quando olham, não conseguem captar o sentimento do outro com quem interage (SOUZA, 2018).

As crianças com Síndrome de Asperger manifestam dificuldade em compreender metáforas, aqui o papel dos familiares e educadores é de extrema importancia, explicar e ensinar os infantos o uso das gírias e ironias com o máximo possível dessas ocorrências no 
momento do ensino, facilitando a aprendizagem e os deixando mais confiáveis e confortáveis. Assim, evita-se a possibiliadade da criança parecer rude e ofensiva, mal educada e propensa a comportamento egocêntrico e inadequado, por falta de compreensão dos estimulos sociais.

Outra particularidade importante a ser considerada é o olhar que os infantos portadores da S.A possuem, em um ambiente muito estimulador, eles ficam estressados, pois são muitos estímulos chamando atenção deles ao mesmo tempo. Também não gostam de mudanças bruscas; assim como, por exemplo, troca dos objetos de lugar, mudança de rotina e de ambiente (SOUZA, 2018).

Como mencionado, para o reconhecimento das caractrerísticas mais sutis do transtorno de Autismo leve ou Asperger, deve ser redobrada a atenção para o diagnóstico efetivo. O que significa dizer que devemos possuir conhecimento aprofundado sobre a síndrome de Asperger e que há necessidade de que mais estudos neste sentido sejam realizados.

Reconhecer um infanto disperso, que se balança ou geme quase todo tempo, com explicito Autismo, não é tão desafiador. Mas, identificar modulações muito sutis de obstáculos sociais em crianças que não têm nenhum diagnóstico é bem dificíl. Compreender a profundidade dos sentimentos das crianças com essa maneira peculiar de ver e perceber o mundo é o primeiro passo para que possamos ajudá-los. (SILVA, GAIATO, REVELES, 2012, p. II).

Ao que tange a comunicação, as crianças Autistas apresentam atribulação na linguagem não verbal, que são os símbolos, sinais, cores e exteriorização do dia a dia como gesto e expressões faciais. Nas habilidades inerentes à linguagem verbal, no caso, a língua falada e na escrita (SILVA, GAIATO, REVELES,2012, p.p.16,17).

É de extrema relevância identificar à capacidade de interpretação da criança frente às formas de comunicação não verbais, essa perspicacia ajuda no diagnóstico do espectro, porque são inumeras as crianças autistas que possui elevado nível de desenvolvimento da fala e com isso acabam minimizando ou mesmo mascarando os sintomas do Autismo.

Sabemos que as interações sociais das crianças são consideradas a partir de padrões aceitáveis de comportamento em cada sociedade. Os infantos Autistas, porém, apresentam inaptidão para interpretar, assimilar e acomodar as convenções comportamentais. Os comportamentos em geral, são estereotipados e repetitivos, como balançar o corpo, as mãos, pular, agitar ou torcer os dedos, bater palmas, ou fazer caretas, por exemplo. Algumas crianças desenvolvem outras manias comportamentais, diferentes das mencionadas, que são realizadas sempre da mesma forma. Ainda existem os comportamentos disruptivos cognitivos que são as mesmice, compulsões, rituais, ou aderencia rigida a alguma regra específica ou arraigados a rotina (SILVA, GAIATO, REVELES, 2012, P.26). 
São inúmeras as peculiaridades alusivas ao Autismo e sua singularidade de desenvolvimento, mas o relevante aqui é primeiramente compreender que esta síndrome, independente do nível de severidade carece de tratamento e salientamos para importância de entender que essa maneira diferente de ser e perceber o mundo são inatas, porém podem ser suavizadas. Para tanto, faz-se urgente compreender e respeitar determinadas limitações.

Vamos agora pensar nos processos que englobam a atuação do Psicopedagogo numa perspectiva inclusiva e com capacidade de identificar, diagnosticar e fazer as intervenções necessárias. Mas o que é Psicopedagogia? A fim de responder esta interrogação é pertinente continuarmos pautados no que nos apresenta literatura.

A psicopedagogia surgiu na Europa no século XX, devido ao imperativo de se pensar sobre as metodologias de aprendizagem humana e principalmente sobre as frustrações escolar. Esses ideais abeirar-se na América do Sul pela Argentina onde recebeu força e se difundiu, chegando ao Brasil na década de 1970 .

André, Ribeiro (2019) cita, Bossa (2007, p. 19) declara que a psicopedagogia como produção de um conhecimento científico originou-se da carestia de melhor compreensão do processo de aprendizagem, e não se basta como aplicação da psicologia à pedagogia.

Ainda em André, Ribeiro (2019), contribuem que para Visca (1987)

A psicopedagogia nasceu como uma ocupação empírica pela necessidade de atender as crianças com dificuldades na aprendizagem, cujas causas eram estudadas pela medicina e psicologia. Com o decorrer do tempo, o que inicialmente foi uma ação subsidiária destas disciplinas, perfilou-se como um conhecimento independente e complementar, possuidor de um objeto de estudo (o processo de aprendizagem) e de recursos diagnósticos, corretores e preventivos próprios. (VISCA, 1987, p. 33)

$\mathrm{O}$ autor argentino divulga que a Psicopedagogia é uma profissão independente, com conteúdo e embasamentos científicos que são complementares e independentes da Psicologia e da Pedagogia.

O Código de Ética da Psicopedagogia (20II), em seu artigo Io, estabelece que (ANDRE, RIBEIRO, 2019):

A psicopedagogia é um campo de atuação da Educação e Saúde que se ocupa do processo de aprendizagem, considerando o sujeito a família, a escola, a sociedade e o contexto sócio-histórico, utilizando procedimentos próprios, fundamentados em diferentes referenciais teóricos. (CEP, 20II)

A psicopedagogia então serve para amenizar possíveis sofrimentos entrelaçados ao processo da problematização do aprendizado. Através de uma revisão bibliográfica, com base em teóricos e estudiosos das áreas de inclusão e de psicopedagogia. Lembramos que a educação infantil tem o compromisso de prover um desenvolvimento fundamentado em qualidade e equidade e a inclusão do aluno com Síndrome de Asperger deve ser observada, 
proporcionando-lhe acolhimento, respeito, saúde no padrão físico, psíquico, social e emocional. Com base no exposto colabora Almeida Júnior:

\begin{abstract}
Refletir sobre a importância do trabalho do psicopedagogo no ambiente escolar inclusivo é imprescindível, devido à necessidade do mesmo conduzir à criança com necessidades educacionais especiais a uma formação sócio interacionista entre o aprender e o compreender, isto é, possibilitá-la a um entendimento em vista daquilo que está sendo mais relevante naquele momento para ela, seja tal representado por meio de valores, sonhos ou fantasias, levando em consideração a comunidade que faz parte do convívio social deste ser. (ALMEIDA JÚNIOR, 20I2, p. 4-5)
\end{abstract}

Já o exercício do psicopedagogo institucional é voltado para o cenário inclusivo, se utiliza de metodologias e procedimentos didáticos diversificados que viabilizem os atendimentos multidisciplinares. O Psicopedagogo Institucional atua conjuntamente com a equipe multidisciplinar, para que ocorra intervenções voltadas para as crianças que apresentam comportamentos atípicos, objetivando mudanças e desenvolvimento destas nos contextos familiar e escolar. Veja a contribuição de Martins com relação a prática institucional do Psicopedagogo:

O psicopedagogo institucional, junto aos professores, poderá ajudá-los a perceberem-se como "aprendizes" e a rever seus modelos de ensinante e de aprendente para que possam desempenhar adequadamente seu papel diante desta nova realidade que demanda o abandono de práticas padronizadas e a negação da homogeneidade. A fim de promover a autonomia da instituição e as competências de seus membros, institui o trabalho coletivo e visa à geração de processos de construção de conhecimento em todos os membros da equipe escolar, valorizando a posição ativa diante do conhecimento e possibilitando que cada participante contribua com seus conhecimentos, vivências e pontos de vista. (MARTINS, 20II, p. 2059)

Não obstante, percebeu-se atracvés do levantamento literário que apesar de existirem políticas com relação a inclusão, há muito a se fazer para que as disposições sejam efetivas no Brasil. O Psicopedagogo ainda encontra desafios para realização de suas práticas didáticas psicopedagógicas, tais como: adesão dos pais, orientação dos professores e encaminhamento dos profissionais de saúde para que as crianças recebam a atenção pertinente. Outro limitador é a ausência da formação continuada de alguns profissionais da assistencia básica aos infantos, não sendo assim especialistas de apoio. Dessa forma, a busca pelo conhecimento, a partir da própria experiencia se faz muitas vezes adotar as estratégias para realizar um trabalho de excelência.

A ciência, os estudos e a formação continuada nos levam a vislumbrar novos horizontes. Através da limitada literatura atualizada sobre crianças autistas, percebemos a necessidade de conhecer e compreender mais sobre o TEA e suas nuances como, principalmente a Sindrome de Arperger, tão recorrente e raramente considerada. 
A discussão teórica sobre a Educação infantil, no curso de pós graduação de Psicopedagogia e Ludopedagogia foi um combustível motivador para expandir o conhecimento e trabalhar as diferenças e desafios do autismo leve ou Sindrome de Asperger, na perspectiva da educação infantil. Mais precisamente através das possibilidades de atuação do Psicopedagogo que não se restringe ao contexto escolar, embora seja de extrema relevância.

Aliás, nesse sentido, Souza (2018) enfatizou que o psicopedagogo deve: ajudar o professor e orientar demais profissionais nas questões pedagógicas e psicopedagógicas; amparar os pais; cooperar com a gestão da escola ou instituição para que exista um relacionamento harmonioso entre todos os integrantes seja na escola ou outra organização e, principalmente, auxiliar a criança que esteja com dificuldade, seja qual for a sua causa. É importante que os familiares, educadores e não obstante, o Psicopedagogo, compreendam e respeitem essas dificuldades das crianças com Sindrome de Asperger, e que tracem estratégias que possam auxiliar essas crianças a se adequarem ao meio em que vivem, mesmo com suas limitações e dificuldades.

\section{CONCLUSÃO}

Concluímos, de acordo com a própria história, que primeiramente o foco na criança era de cuidado com a saúde e higiene. Atualmente, sabe-se que os cuidados com as crianças vêm sendo ampliado.

Kremer (2006), citados em Gonring (2016) adverte para obrigação de entendermos as crianças como cidadãos e ao mesmo tempo como produtores de resultado da cultura. Com base nesta compreensão, a educação infantil abandona a fase de somente prestar atenção ao físicohigiênico. Hoje, a educação infantil não é simplesmente um período de assistencialismo, como um tempo de espera para que a escolaridade efetivamente se inicie.

Logo, se a criança é reconhecida como uma cidadã com direitos ela deve acompanhar a atual cultura dinâmica. Para tanto se faz necessário que a educação infantil, aquela que começa no berço, assuma medidas educativas criteriosas que permitam a aprendizagem e desenvolvimento desses cidadãos. Par que seja possível colheita ao cultivo de valores acordados como importantes para o conjunto da sociedade entre os quais está a inclusão das crianças com necessidades especiais, devemos nos manter atuantes. Não obstante, percebe-se tímida a atuação do Psicopedagogo nos contextos que deveriam estar prestando serviços ativamente, a exemplo disso, nas Escolas de Educação infantil. O Psicopedagogo é profissional de extrema importância, especialista habilitado em compreender a criança como um indivíduo que possui valor em si mesmo e delas extrair o seu melhor auxiliando-as no seu 
amplo desenvolvimento, viabilizando saúde e bem-estar não somente para as crianças com alguma necessidade especial, mas, para todos.

\section{REFERÊNCIAS}

ALMEIDA, Júnior. C. B. O psicopedagogo na educação especial. In: Estação Científica, Macapá, v. 2, n. I, p. oI-Io, janeiro-junho de 2012.

AMARAL, Shirlena; LYRIO, Ana. SEMINÁRIO INTERNACIONAL DE EDUCAÇÃO, TECNOLOGIA E SOCIEDADE: ENSINO HÍBRIDO. Núcleo de Educação Online. A tecnologia como ferramenta para aprendizagem das crianças com Síndrome da Asperger na Educação Infantil. FAC CAT. 24ํ․ de 12-18 de novembro de 2019.

AMERICAN PSYCHIATRIC ASSOCIATION. DSM-5 - Manual Diagnóstico e Estatístico de Transtornos Mentais. Porto Alegre: Artmed, 2014.

AMERICAN PSYCHIATRIC ASSOCIATION. DSM-IV - Manual Diagnóstico e Estatístico de Transtornos Mentais. Porto Alegre: Artmed, 2002.

ANDRÉ, Bianka; RIBEIRO, Ana. Reflexões sobre as possibilidades de atuação do psicopedagogo institucional e o processo de inclusão escolar. Revista Philologus, Círculo Fluminense de Estudos Filológicos e Linguísticos. Ano 25, $\mathrm{N}^{\circ}$ 73. Rio de Janeiro: CiFEFiL, janeiro-abril de 2019 .

BOSSA, Nádia. A psicopedagogia no Brasil: contribuições a partir da prática. 3. ed. Porto Alegre: Artmed, 2007.

BOSSA, Nádia. Dificuldades de aprendizagem: o que são? Como tratá-las? São Paulo: Artmed, 2000.

GONRING, Vilmara. Seminário Nacional de Educação Especial/XV Seminário Capixaba de Educação Inclusiva. Movimentos para a inclusão escolar de uma criança com Síndrome de Asperger Educação Infantil. 20-22 setembro de 2016. Vitória- ES. Anais do Seminário Nacional de Educação Especial e do Seminário Capixaba de Educação Inclusiva. V.ı, 2016.

KLIN, Ami. Autismo e Síndrome de Asperger: uma visão geral. Revista Brasileira de Psiquiatria. 2006, n. 28 (supl. I): S3-II.

MARTINS, Bárbara. Contribuições da psicopedagogia institucional à inclusão da criança com deficiência na escola regular. In: VII Encontro da Associação Brasileira de Pesquisadores em educação especial. Londrina, 20II. Disponível em:http://www.uel.br/eventos/congressomultidisciplinar/pages/arquivos/anais/20II/FOR $\mathrm{MACAO} /$ 192-20II 
MELO, Elda; SANTOS, Camila. Políticas Públicas na Educação Brasileira: educação infantil e anos iniciais do ensino fundamental 2. Capítulo 3. Educação Inclusiva e autismo Infantil, p. 19-29. Ponta Grossa, PR: Atena Editora, 2019.

Brasil. Lei no 9394/96. Ministério da Educação e do Desporto. Conselho Nacional de Educação/ Câmara de Educação Básica. Lei de Diretrizes e Bases da Educação Nacional. Brasília: 1996.

. Ministério da Educação e do Desporto. Diretrizes Nacionais para a Educação Especial na Educação Básica/Secretaria de Educação Especial. Brasília: MEC/ SEESP, 20or.

Ministério da Educação e do Desporto. Referencial Curricular Nacional para a Educação Infantil: estratégias e orientações para a educação de crianças com necessidades educacionais especiais. Brasília: MEC/SEF/SEESP, 2000.

SENA, Tito. Manual Diagnóstico e Estatístico de Transtornos Mentais, DSM-5 Estatísticas e Ciências Humanas: Inflexões sobre as normalizações e normatizações. INTERthesis. Doutorado Interdisciplinar em Ciências Humanas- UFSC- Florianópolis, SC, n.2, p.96-II7, jul-dez.2014

SILVA, Ana Beatriz Barbosa; GAIATO, Mayra Bonifácio; REVELES, Leandro Thadeu. Mundo Singular: entenda o autismo. ${ }^{\underline{a}}$ Ed. P.II. São Paulo, Editora Fontanar, 2012.

SOUZA, Elinde Magna de. Síndromes e transtornos na educação: Síndrome de Asperger. 2018. 20 FLS. Trabalho de conclusão de curso de Pedagogia - Universidade Pitágoras Unopar, Arapongas, 2018.

VISCA, Jorge. Clínica Psicopedagógica: Epistemologia Convergente. Porto Alegre: Artes médicas, 1987 . 